\title{
Pressure Induced Effects During In Situ Characterization of Supported Metal Catalysts
}

Monia R. Nielsen ${ }^{1}$, Xi Liu ${ }^{3}$, Jakob B. Wagner ${ }^{1}$, Christian D. Damsgaard ${ }^{1,2}$, Thomas W. Hansen ${ }^{1}$, Max Schumann $^{4}$, Anker D. Jensen ${ }^{4}$ and Jakob M. Christensen ${ }^{4}$

1. Center for Electron Nanoscopy, Technical University of Denmark, Lyngby, Denmark

2. Department of Physics, Technical University of Denmark, Lyngby, Denmark

3.SynCat@Beijing, Synfuels China Technology Co., Ltd, Beijing, China

4. Department of Chemical and Biochemical Engineering, Technical University of Denmark, Lyngby, Denmark

A combination of different in situ techniques were used to investigate the activation and deactivation processes of supported metal catalysts such as $\alpha-\mathrm{Fe}_{2} \mathrm{O}_{3}$ for Fischer-Tropsch synthesis and $\mathrm{Rh}$ based catalysts for the synthesis of higher alcohols. The pressure was varied between a few millibars and atmospheric pressure.

Iron-based catalysts are typically used commercially for Fischer-Tropsch synthesis, as they are cheaper than their cobalt and ruthenium-based counterparts [1]. Therefore, looking at their activation process is critical for gaining further insight on the nature of the active sites in order to further enhance their performance. $\alpha-\mathrm{Fe}_{2} \mathrm{O}_{3}$, used as precursor for Fischer-Tropsch catalysts, is typically activated in either $\mathrm{H}_{2}$, $\mathrm{CO}$ or syngas before synthesis reaction. As $\mathrm{CO}$ or syngas activation lead to iron carbides and iron oxides we look at the unsupported $\alpha-\mathrm{Fe}_{2} \mathrm{O}_{3}$ precursors exposed to hydrogen to gain information about their evolution in time under in situ conditions. The activation involve interaction between the precursor, $\alpha-$ $\mathrm{Fe}_{2} \mathrm{O}_{3}$, and the surrounding gas constituents, in this case hydrogen, which is not only altering the morphology and surface structure but eventually also the catalytic performance.

To better understand the gas-induced shape evolution of the $\alpha-\mathrm{Fe}_{2} \mathrm{O}_{3}$ precursor, we look at the activation process at different pressures. First, we look at low pressure (a few millibars) using a $\mathrm{C}_{\mathrm{S}}$-corrected FEI Titan 80-300 environmental TEM and a DENSsolution Wildfire S3 MEMS based heating holder, see Figure 1. Under these conditions, the catalyst can be reduced from $\mathrm{Fe}_{2} \mathrm{O}_{3}$ to $\mathrm{Fe}_{3} \mathrm{O}_{4}$ and finally to metallic Fe. In order to further understand what happens at higher pressure, a DENSsolutions Climate system was used. Here the catalyst can be exposed to the same gas composition at pressures up to $1 \mathrm{bar}$. While reducing $\alpha-\mathrm{Fe}_{2} \mathrm{O}_{3}$ to $\mathrm{Fe}_{3} \mathrm{O}_{4}$ and further to $\alpha-\mathrm{Fe}$, we aim to look into the shape evolution of iron and to demonstrate the difference that occur at different pressures, which is an important result of the influence of pressure in terms of obtaining the real structure-activity correlation for nanoparticles in reaction condition. Furthermore, since the high electron energies and current densities typically used in HRTEM measurements often causes beam induced dynamic processes, we also want to address some of the effects that occur at higher pressures.

In order to further understand pressure effects under in situ investigations of supported metal catalysts, strong metal support interactions (SMSI) were investigated on Rh based catalysts for the synthesis of higher alcohols, see Figure 2.

Reference:

[1] X. Liu, et al, ACS Catalysis 7 (2017), p. 4867. 


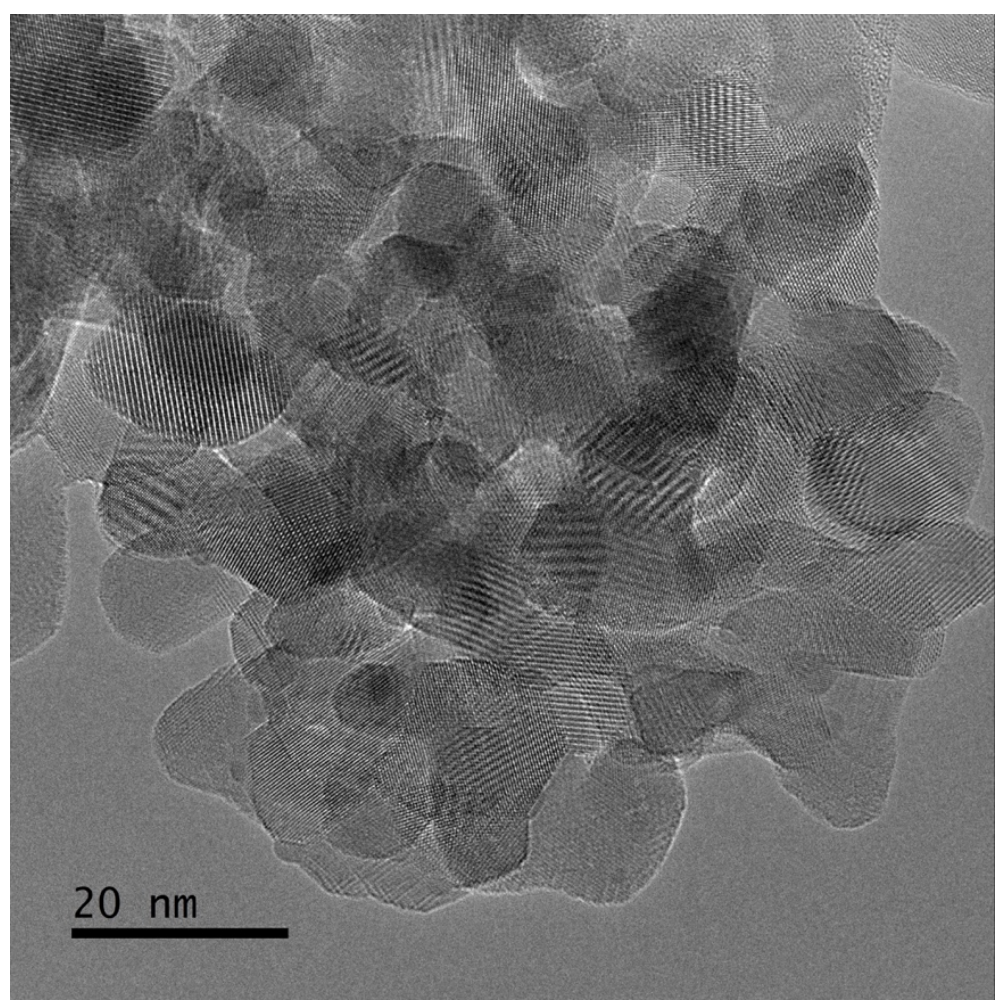

Figure 1. Iron oxide particles showing the general structure, currently in the $\mathrm{Fe}_{2} \mathrm{O}_{3}$-state.

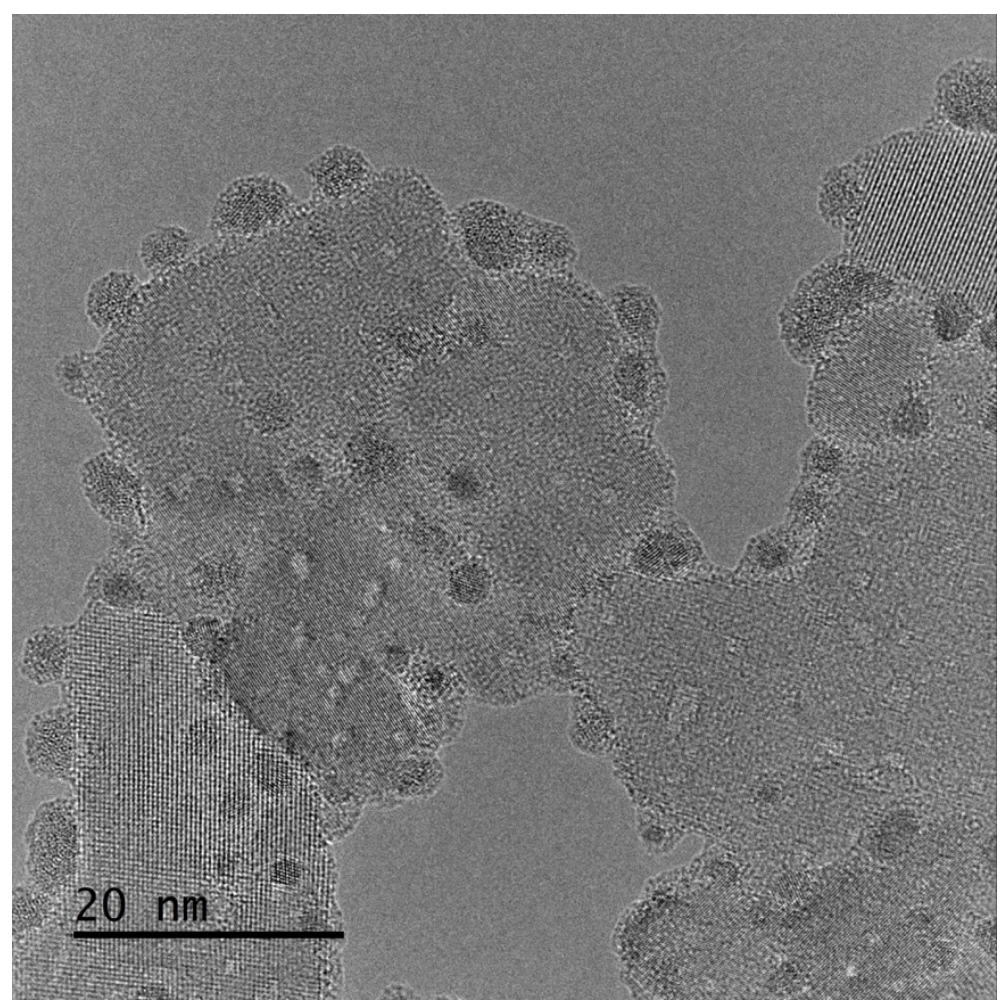

Figure 2. $\mathrm{Rh}$ particles on $\mathrm{TiO}_{2}$ support illustrating the strong metal support interaction (SMSI). 